\title{
A New Mixing Method for Lightweight Concrete with Oil Palm Shell as Coarse Aggregate
}

\author{
Leong Tatt Loh $^{1 *}$, Ming Kun Yew ${ }^{1}$ and Ming Chian Yew ${ }^{1}$ \\ ${ }^{1}$ Facutly of Engineering and Science, Universiti Tunku Abdul Rahman, 41600 Kajang Selangor, \\ Malaysia
}

\begin{abstract}
Oil Palm Shell (OPS) is the solid waste product from the palm oil sector of the agricultural industry. The substitution of coarse aggregate in concrete with OPS to produce lightweight concrete (LWC) had been researched since two decades ago. The author has discovered fluctuation on the performance of OPSLWC. One of the factors is the workability. As an initiative to enhance the performance of OPSLWC, the author proposes a new mixing method (NMM) modified from the mix design of selfcompacting concrete (SCC). The effects of the NMM on the workability, uniformity, compressive strength and splitting tensile strength are investigated. The workability of the NMM is $25.5 \%$ higher than the conventional method (CM). The compressive strength shows an improvement of $5.76 \%$; while the splitting tensile strength is increased by $22.35 \%$. The new findings of this research have shown a positive impact on the concrete industry.
\end{abstract}

Keywords. Oil palm shell, New mixing method, Lightweight concrete, Compressive strength, Splitting tensile strength

\section{Introduction}

The disposal of solid waste has become one of the main issues for the palm oil industry. Oil palm shell (OPS) is one of the waste products from this industry. In 2016, Malaysia was marked as the world second largest exporter with the production of 16.05 million tonnes of palm oil, which contributed to $36.75 \%$ of the world palm oil trade [1]. According to the Malaysian Palm Oil Board (MPOB), approximately 5.84 million tonnes of OPS had been produced in 2016 based on calculation. As an initiative to counter this problem, researches of the substitution of crushed OPS as coarse aggregates in concrete had been started since 1984 in Malaysia [2]. From previous researches, the compressive strength of oil palm shell lightweight concrete (OPSLWC) with the presence and absence of cementitious materials fell within $35 \mathrm{MPa}$ and was not less than $20 \mathrm{MPa}$, which met the requirement for lightweight concrete in structural application [3].

However, the author has found fluctuation on the performance of OPSLWC when conducting research. One of the factors that cause the inconsistency is the workability of the mixture. As an initiative to enhance the consistency of the flowability of OPSLWC, the

\footnotetext{
* Corresponding author: dylantatt06@gmail.com
} 
author proposes a new mixing method (NMM) modified from the mix design method of self-compacting concrete (SCC), which is a special concrete with high workability. SCC can consolidate itself by self-weight without external forces. It is cohesive enough to be handled without segregation or bleeding. It was first proposed by Okamura in 1986 and the first prototype was first built in the University of Tokyo by Ozawa in 1988 [4,5]. The general idea comes from one of the mix design method of SCC, which consists of two phases, the liquid phase and the solid phase [6]. The liquid phase is made up of the cement paste; solid phase is defined by the aggregates.

This paper is to investigate the effect of the proposed mixing methodology on the performance of OPSLWC, which includes workability, compressive strength, splitting tensile strength and uniformity. To the author's knowledge, this is a new method to produce OPSLWC, which has no available information.

\section{Experimental details}

\subsection{Materials}

\subsubsection{Cement}

Ordinary Portland Cement (OPC) in accordance with MS EN 197-1:2014 is used for all the samples in this research [7]. The technical specifications of the OPC used are summarised in Table 1.

Table 1. Specifications of OPC.

\begin{tabular}{lll|llllll}
\hline \multicolumn{2}{c|}{ Physical Specifications } & \multicolumn{5}{c}{ Chemical Composition (\%) } \\
\hline LOI & $\begin{array}{c}\text { Specific } \\
\text { Gravity }\end{array}$ & $\begin{array}{c}\text { Blaine's } \\
\text { specific } \\
\text { surface } \\
\text { area } \\
\left(\mathrm{cm}^{2} / \mathrm{g}\right)\end{array}$ & $\mathrm{SiO}_{2}$ & $\mathrm{CaO}$ & $\mathrm{Fe}_{2} \mathrm{O}_{3}$ & $\mathrm{MgO}$ & $\mathrm{Al}_{2} \mathrm{O}_{3}$ & $\mathrm{SO}_{3}$ \\
\hline 0.64 & 3.14 & 3510 & 21.28 & 64.64 & 3.36 & 2.06 & 5.60 & 2.14 \\
\hline
\end{tabular}

\subsubsection{Mixing water and superplasticizers (SP)}

The mixing water in this study was potable water from the tap. High performance water reducer, Master Glenium ${ }^{\circledR S K Y} 8808$ manufactured by BASF was included into all mixes in a small amount to enhance the workability of fresh concrete.

\subsubsection{Aggregates}

Old OPS which had been disposed of for more than 6 months, were fully substituted conventional coarse aggregates in all the mixes in this study. Old OPS contain less than $2 \%$ of fibers on their surface. This gives a better bonding between the mortar and OPS grains and results in a higher strength performance [8]. All the OPS used were sieved through 10 $\mathrm{mm}$ sieve. Before casting, they were fully submerged in water for 1 day. After that, they were removed from the water and were air-dried to saturated surface dry (SSD) condition under room temperature prior to mixing. This is to prevent additional water from the 
immersed OPS added to the concrete mixture. The physical properties of the OPS used are illustrated in Table 2.

Fine aggregate in this research was domestic mining sand. The specific gravity is 2.63; fineness modulus is 2.83; water absorption is $0.95 \%$ and maximum grain size is 4.75 $\mathrm{mm}$. They were sieved through $4.75 \mathrm{~mm}$ sieve and sun dried before being stored in plastic containers with covers to prevent air moisture to enter.

Table 2. Physical Properties of OPS.

\begin{tabular}{lc}
\hline Physical Property & OPS \\
\hline Maximum size (mm) & 10 \\
Specific gravity (SSD state) & 1.30 \\
Aggregate impact value (\%) & 2.33 \\
Compacted bulk density & 632 \\
$\left(\mathrm{~kg} / \mathrm{m}^{3}\right)$ & \\
Water absorption (\%) & 2.34 \\
\hline
\end{tabular}

\subsection{Design of the mix}

The amount of water, cement, SP, OPS, and fine aggregates remains unchanged for both sets of mixes. The amount of each constituent in the concrete is illustrated in Table 3. Each set of the mix is produced by different mixing methods. The mix produced in CM is named as OPSLWC_C, while the mixed cast in NMM is named as OPSLWC_N.

Table 3. Mix Design of All Mixes.

\begin{tabular}{cccccc}
\hline Mix & $\begin{array}{c}\text { Cement } \\
\left(\mathrm{kg} / \mathrm{m}^{3}\right)\end{array}$ & $\begin{array}{c}\text { Fine } \\
\text { aggregate } \\
\left(\mathrm{kg} / \mathrm{m}^{3}\right)\end{array}$ & $\begin{array}{c}\text { OPS } \\
\left(\mathrm{kg} / \mathrm{m}^{3}\right)\end{array}$ & $\begin{array}{c}\text { Water } \\
\left(\mathrm{kg} / \mathrm{m}^{3}\right)\end{array}$ & SP (\%) \\
\hline OPSLWC_N & 515 & 1000 & 290 & 170 & 2.0 \\
OPSLWC_C & 515 & 1000 & 290 & 170 & 2.0 \\
\hline
\end{tabular}

\subsection{Experimental procedures}

The procedures to produce all the mixes are described in this section. Two different types of mixing procedures are used in this research. The steps of these two methods are summarised in Figure 1. The CM comprises of dry mix and wet mix with a total mixing time of 7 minutes. The NMM is developed as a modification from the mix design of selfcompacting concrete (SCC), which comprises of the liquid phase and a solid phase in a total mixing time of 6 minutes [6]. Before placing, the slump value is measured to determine the workability of the mixture. The molds are oiled before casting and are placed on shaking table for compaction to minimize air voids in the mix. The specimens are removed from the moulds approximately 24 hours after placing. After that, all the demoulded samples are fully immersed in water in a curing tank until the required age for testing. Non-destructive test (NDT), ultrasonic pulse velocity test (UPV) is carried out to determine the conformity of the concrete. For each mixture, cubes with a volume of 100 $\mathrm{mm}^{3}$ are cast to test for compressive strength at 1,7 and 28 days. The splitting tensile strength at 7 and 28 days is examined with cylinders. 


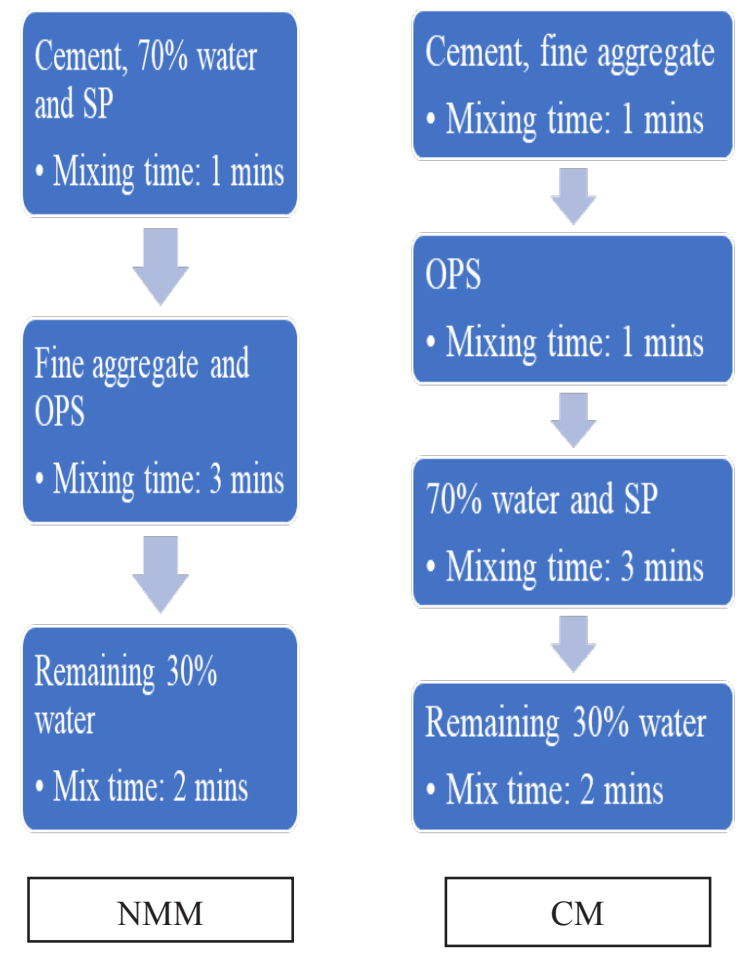

Fig.1. The procedures of NMM and CM.

\section{Results and discussion}

\subsection{Density}

Fresh density (FD), demoulded density (DD) and oven-dried density (ODD) were measured for both mixes. FD, DD, and ODD of the mixes of different mixing method are shown in Fig. 2. The ODD of all mixes fell in the range of $1976-1985 \mathrm{~kg} / \mathrm{m}^{3}$, which marked them as structural lightweight concrete. Structural lightweight concrete is defined as concrete with an ODD of less than $2000 \mathrm{~kg} / \mathrm{m}^{3}$ [9]. The differences in densities of both mixes are not significant and negligible. In other words, the mixing method has no effect on the densities, the densities are mainly affected by the proportion of the constituents in the concrete.

\subsection{Workability}

Workability is the measure for the consistency of concrete. Slump test is carried out to quantify the flowability. The mix proportion for both sets of mixtures is kept constant to examine the effect of the mixing procedures on the workability. From the results illustrated in Fig. 3, both mixes are highly workable, the workability of OPSLWC_N is $25.5 \%$ better than that of OPSLWC_C. From previous studies, the addition time of SP influences the flowability [10]. In NMM, water, SP and OPC are mixed initially. As SP only reacts with OPC, the early addition of SP without the presence of aggregates expedites the reaction between SP and OPC. This eventually enhances the workability of the mix with a shorter total mixing time. 


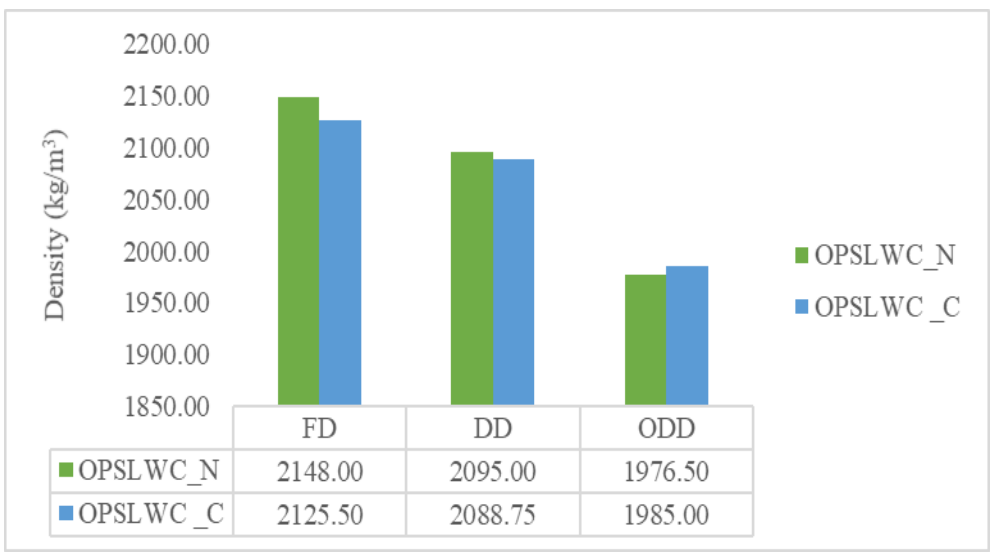

Fig. 2. Densities of the Mixes.

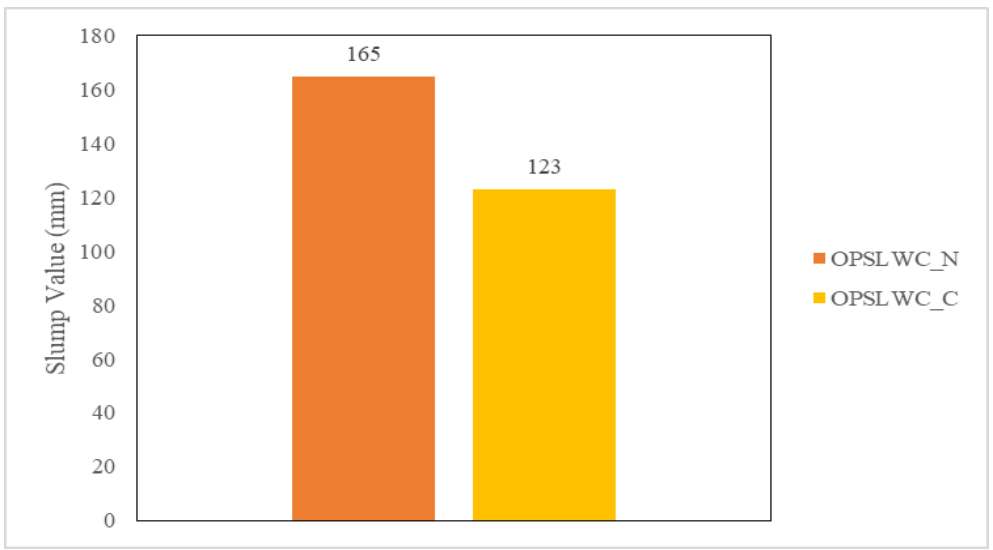

Fig. 3. Workability of the Mixes.

\subsection{Ultrasonic Pulse Velocity (UPV) test}

UPV test is a non-destructive test (NDT) for the conformity of concrete and the presence of cracks and voids. The influence on the uniformity of concrete by different mixing procedures is studied. The results are tabulated in Table 4. Concrete with UPV values within $3.66 \mathrm{~km} / \mathrm{s}$ to $4.58 \mathrm{~km} / \mathrm{s}$ is categorised as good grading concrete [11]. At 1-day age, the pulse velocity of OPSLWC_C is slightly higher than that of OPSLWC_N, which are $3.51 \mathrm{~km} / \mathrm{s}$ and $3.49 \mathrm{~km} / \mathrm{s}$ respectively. But, the pulse velocities of OPSLWC_N are higher at 7-days and 28 -days, which are $3.56 \mathrm{~km} / \mathrm{s}$ and $3.59 \mathrm{~km} / \mathrm{s}$ respectively. While the pulse velocities of OPSLWC_C at 7-days and 28-days are $3.54 \mathrm{~km} / \mathrm{s}$ and $3.57 \mathrm{~km} / \mathrm{s}$ respectively. The slight improvement is due to the more uniform mix of OPSLWC_N with lesser voids in the concrete due to the higher workability.

\subsection{Compressive strength and splitting tensile strength}

Compressive strength at 1,7 and 28-days and splitting tensile strength at 7 and 28-days of all set of specimens are described in Table 5. A similar trend as UPV test is observed in the compression test. The early strength (1-day) of OPSLWC_C is higher than that of OPSLWC_N, which are 21.13 MPa and 20.02 MPa respectively. The low early strength is 
due to the dispersion of cement particles by the SP added [12]. The dispersion of cement particles in OPSLWC_N is more rigorous as the reaction between cement and SP is expedited. However, OPSLWC_N shows a better growth of strength under water curing as the 7 and 28-days compressive strengths are more prominent. Comparatively, the 7-days compressive strength of OPSLWC_N is $5.76 \%$ higher and the 28-days compressive strength of OPSLWC_N is $5.72 \%$. At the later age, the dispersed cement particles are also fully hydrated.

In term of splitting tensile strength, the 7-days strength is lower in OPSLWC_N, but the 28-days strength is higher in OPSLWC_N. The effect of the mixing process is more pronounced on the splitting tensile strength as the 28-days strength of OPSLWC_N is $22.35 \%$ higher than that of OPSLWC_C. The splitting tensile strengths of OPSLWC_ $\overline{\mathrm{N}}$ and OPSLWC_C are $7.6 \%$ and $6.57 \%$ of their respective compressive strengths, which are relatively lower as the splitting tensile strength is usually approximately one-tenth of the compressive strength [13]. This is caused by the weaker bonding between the cement mortar and the OPS [14].

The correlation between UPV and its corresponding compressive strength as shown in Fig. 4 with a $\mathrm{R}^{2}$ of 0.97 . Hence, Eq (1) is proposed to estimate the compressive strength with given UPV values.

$\mathrm{UPV}=2.7204\left(f_{c u}\right)^{0.0831}$

where $f_{c u}$ is the compressive strength in MPa and UPV is the ultrasonic pulse velocity in $\mathrm{km} / \mathrm{s}$.

Table 4. UPV at 1,7 and 28-days of the Mixes.

\begin{tabular}{cccc}
\hline \multirow{2}{*}{ Type of Mix } & \multicolumn{3}{c}{ UPV $(\mathrm{km} / \mathrm{s})$} \\
\cline { 2 - 4 } & 1-day & 7-days & 28-days \\
\hline OPSLWC_N & 3.49 & 3.56 & 3.59 \\
OPSLWC_C & 3.51 & 3.54 & 3.57 \\
\hline
\end{tabular}

Table 5. Compressive Strength and Splitting Tensile Strength of the Mixes.

\begin{tabular}{|c|c|c|c|c|c|}
\hline \multirow{2}{*}{ Mix } & \multicolumn{3}{|c|}{ Compressive Strength (MPa) } & \multicolumn{2}{|c|}{$\begin{array}{l}\text { Splitting Tensile Strength } \\
(\mathrm{MPa})\end{array}$} \\
\hline & 1-day & 7-days & 28-days & 7-days & 28-days \\
\hline OPSLWC_N & 20.02 & 25.87 & 27.37 & 1.20 & 2.08 \\
\hline OPSLWC_C & 21.13 & 24.46 & 25.89 & 1.36 & 1.70 \\
\hline
\end{tabular}




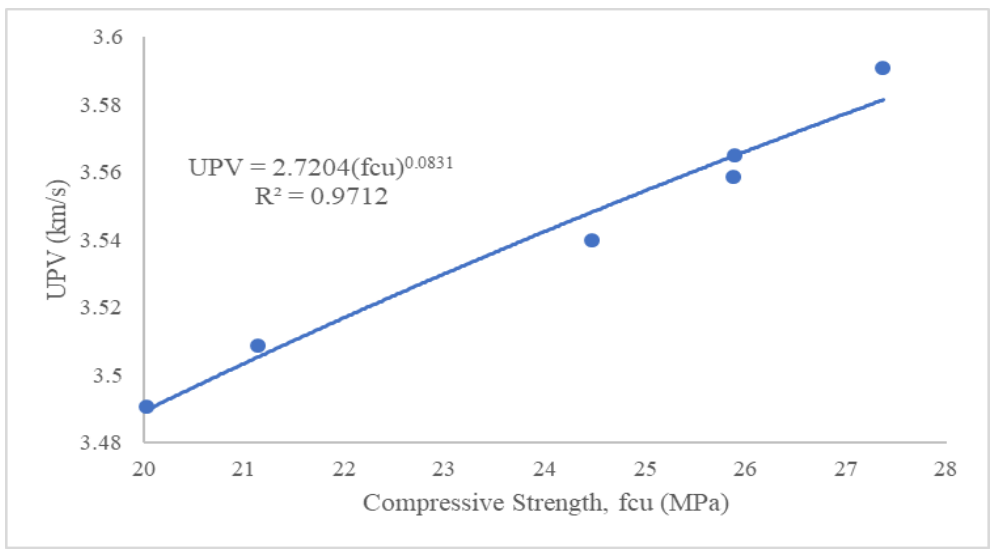

Fig.4. The Relationship between UPV and Compressive Strength

\section{Conclusions}

From this research, the following conclusions are drawn:

1. The workability of OPSLWC_N is $25.5 \%$ higher than that of OPSLWC_C. Hence, the workability is enhanced in the NMM.

2. The improvement on UPV is not so significant. However, the improvement is due to the lesser voids in OPSLWC_N.

3. The compressive strength of OPSLWC_N as compared to OPSLWC_C is increased by $5.76 \%$ in 7 - days and $5.72 \%$ in 28 days.

4. The 28-days splitting tensile strength of OPSLWC_N is $22.35 \%$ higher than that of OPSLWC_C.

\section{References}

1. Malaysian Palm Oil Council, Annual Report 2016, Selangor: Malaysian Palm Oil Council. (2016)

2. A. Ali, A. Abdullah, S. K. A. Salam, A. A. Rahim, Basic Strength Properties of Lightweight Concrete Using Agricultural Wastes as Aggregates. In: International Conference on Low Cost Housing for Developing Countries, 143-146. (1984)

3. P. Shafigh, H. Mahmud, M. Z. Jumaat, M. Zargar, Agricultural wastes as aggregate in concrete mixtures - A review. Constr. Build. Mater., 53, 110-117. (2014)

4. H. Okamura, Self-Compacting High-Performance Concrete, Concr. Int. Design Constr., 19(7), 50-54. (1997)

5. K. Ozawa, K. Maekawa, M. Kunishima, H. Okamura, Development of high performance concrete based on the durability design of concrete structures., In EASEC-2, 1, 445-450. (1989)

6. C. Shi, Z. Wu, K. X. Lv, L. Wu, A review on mixture design methods for selfcompacting concrete. Constr. Build. Mater., 84, 387-398. (2015)

7. MS EN 197-1:2014, Cement - Part 1: Composition, specifications and conformity criteria for common cements, Department of Standards Malaysia. (2014) 
8. P. Shafigh, M.Z. Jumaat, H. Mahmud, Oil palm shell as a lightweight aggregate for producing high strength lightweight concrete. Constr. Build. Mater., 25, 18481853. (2011)

9. [1], Properties of lightweight concrete. Advanced Concrete Technology Processes., 3-29. (Butterworth-Heinemann, Oxford, 2003)

10. C. A. Anagnostopoulos, Effect of different superplasticizers on the physical and mechanical properties of cement grouts. Constr. Build. Mater., 50, 162-168. (2014)

11. A. M. Neville, Properties of concrete. 5th ed. London: Pearson Education Limited. (2011)

12. J. W. Peng, D. H. Deng, H. Huang, Q. Yuan, J. G. Peng, Influence of superplasticizer on the rheology of fresh cement asphalt paste. Case Stud. Constr. Mater., (3), 9-18. (2015)

13. W. T. Lin, A. Cheng, R. Huang, T. C. Cheng, A method for testing the strength of concrete using uniaxial direct tension. J. Chin. Inst. Eng., 36(3), 295-303. (2013)

14. M. K. Yew, H. Madmud, B. C. Ang, M. C. Yew, Effects of heat treatment on oil palm shell coarse aggregates for high strength lightweight concrete. Mater. Des., 54, 702-707. (2014) 